\title{
A Descriptive Profile of All Adapted Physical Education Programs of Study for Master's Degrees in the United States of America
}

\author{
Jiabei Zhang, Kristal Wheaton, Amanda Rapelje, Christopher Farr, Kristin Cowell, and \\ Zezhao Chen \\ Western Michigan University, the United States of America
}

\begin{abstract}
Master's degree programs in adapted physical education (APE) are offered in universities in the United States of America. The review of literature revealed a research problem that a descriptive profile for all such programs could not be found. This problem can be solved through analyzing similarities and differences among their programs of study. The purpose of this study was to analyze all programs of study for master's degrees in APE. All such programs of study were downloaded from websites and their data about program characteristics were identified and collected. All courses specified in each program of study were coded into one of the four components: core, professional, elective, and capstone. The courses in each component were grouped. The mean of credit hours for all programs of study, the mean credit hours in each component, and the percentage of each course group, were calculated. The results obtained in this study resulted in a descriptive profile for all APE master's degree programs of study with multiple characteristics and course groups. This profile is a significant contribution made by this study. It is clear that this profile is useful for professionals to develop and revise an APE master's degree program of study.
\end{abstract}

\section{Introduction}

A descriptive profile is defined as an overview of all programs of study for master's degrees in adapted physical education (APE) offered in the United States of America in this article. This article also defines a program of study as a comprehensive and structured coursework plan for delivering academic education in APE to prepare students for earning a master's degree and a professional endorsement for a career success in teaching children and youth with disabilities APE classes in schools. Basic components included in a program of study generally include the specific title of courses, the number of credit hours, the method of delivering courses, the sequence of offering courses, the type of master's degrees, and so on. These components are served as basic variables used for analyzing and abstracting a descriptive of all programs study for master's degrees in APE offered in the United States of America.

A master's degree is a type of graduate academic degree earned after the completion of an undergraduate academic degree. It is granted to people who have undergone study demonstrating a mastery level of competencies in a specific field of professional practice. The demonstration of this mastery level of competencies is documented through the completion of a list of courses specified in the program of study [1] [2]. A master's degree in APE is therefore awarded to a person upon graduation from a university by completing a program of study in the area of APE.

The master's degree program in APE was initiated after a nationwide effort to develop competencies was made for preparing APE teachers since 1971 [3] [4]. In the1970s, APE leaders believed that specialized training in APE should be designed primarily for the graduate level, which was based on their belief that APE teachers should have a strong background and in-depth training in the liberal arts and in physical education pedagogy. Ersing and Wheeler [5] did a survey of APE professional preparation. The results of this survey showed that 24 in 178 universities offered programs of study to prepare APE teachers. These programs of study in APE were developed based on professional competencies.

Over the years 1971-1972, a nationwide effort to develop the competencies for APE teachers occurred [3]. It resulted in that a list of competencies needed for delivering APE service to children and youth with disabilities were tabulated into six categories (i.e., biological, sociological, psychological, philosophical, assessment, and curriculum). In each category, subcategories were also created. In each of these subcategories, multiple specific competencies were then developed. Since then, the APE competencies have been extensively revised and updated (e.g., Adapted Physical Education National Standards [APENS]) [6].

APENS were developed in 1995. These standards were revised over the years 2003-2006 to reflect current knowledge and practice in the APE field [6]. A total of 15 standards were presented, including human development, motor behavior, exercise 
science, measurement and evaluation, history and philosophy, curriculum theory and development, unique attributes of learners, assessment, instructional design and planning, teaching, consultation and staff development, student and program evaluation, continuing education, ethics, and communication. Multiple and specific competencies for APE teachers were then developed for each of the 15 standards. These standards have been infused in APE training programs [6] that are currently offered in the nation.

Zhang, Rapelje, Farr, Cowell, and Chen [7] found that based on an online search result, a total of 31 colleges and universities in the United States of America are currently posting their programs of study for a master's degree or equivalent in APE. These programs of study require each accepted student to have an undergraduate degree (e.g., Bachelor of Art and Bachelor of Science) and to complete a certain amount of credit hours (e.g., 33) of coursework in different components (e.g., core, professional, elective, and capstone courses) within a designated period of time (e.g., 2 years). As these programs of study were developed in theses colleges and universities based on APENS, similarities between these programs of study can be identified, while differences among these programs of study exist as well [2].

Many similarities and differences among these programs of study for a master's degree in APE in the United States of America can be identified. Several examples of the similarities are that most programs of study for a master's degree in APE in United States of America require a student to complete 33 credit hours for a master's degree, to complete 3 APE courses in the component of specialization, and to complete a practicum course in teaching children and youth with disabilities APE classes in schools. Several examples of the differences are that some programs of study for a master's degree in APE in the United states of America require a student to take 37 credit hours for a master's degree, to take more than 5 APE courses in the component of specialization, and not need to complete a practicum course in teaching children and youth with disabilities APE classes in schools.

Then, what are specific primary similarities and differences among these programs of study for a master's degree in APE in the United States of America? Can a descriptive profile be developed based upon the programs of study posted online? The review of APE research literature revealed that the primary similarities and differences have yet to be identified and a descriptive profile has yet to be developed. The purpose of this study was to identify the primary similarities and differences and to develop a profile based on multiple variables in the programs of study for APE master's degrees offered in colleges and universities in the United States of America. The multiple variables being studied include the program names, type of degrees, credit hours, characteristics of the programs, course groups in the program components, and the top specific courses in each course group.

\section{The Literature Review}

The master's degree program in APE first initiated in the 1970s [3] [4] was historically built up based on previous APE competencies research work by several researchers and practitioners. In 1950, Evelyn Davis was the first person to state teacher training competencies in APE [1] [8]. The focus of her dissertation was first placed on competencies needed to work with students with orthopedically impairments. Although these training competencies were created based on students with orthopedically impairments, not other types of disabilities (e.g., intellectual disabilities, learning disabilities, autism, emotional disturbances, and other health impairments). These competencies were served as a basis for developing competencies for teaching students with all types of disabilities.

In 1954, Snyder and Scott published the first book on professional preparation in health, physical education, and recreation [1] [9]. This book includes an organization plan for competency-based education, in which four columns are listed: (a) presenting problems to be met by students, (b) selected competencies needed to meet the problems, (c) selected experiences to develop the competencies, and (d) resource areas. For example, "to comprehend the needs of children of different age-grade groups" is a problem listed in (a), "appreciates the hereditary factors in child growth and development" is a competency selected in (b), "studies the latest medical findings concerning the needs of children" is a competency selected in (c), and "child growth and development" is a resource area in (d).

Although all competencies developed based on the organization plan included in the book by Snyder and Scott were not intended for teaching students with all types of disabilities physical education skills and physical activities [9], these competencies have strongly influenced APE researchers and practitioners through the 1950s and 1960s [1]. Over this period of time, competencies for teaching students with disabilities APE and adapted physical activities have been developed by several APE professionals. However, not until 1971-1972, did a nationwide effort to develop competencies for APE teachers occur [1]. A list of APE competencies, for example, was developed by a series of institutes funded by the Bureau of Education for the Handicapped. All competencies developed during this period of time provided a basis to develop the academic preparation program for training APE teachers.

Professionals in California were among the first to undertake the task of establishing competencies for the preparation of APE teachers [1] [10]. In 1978, 
California Emphasis Credential in APE was approved for preparing APE teachers. This credential lists required competencies for training APE teachers in seven areas with percentages in the total, including (1) biological foundations, 20\%; (2) sociological foundation, 5\%; (3) psychomotor foundations, 20\%; (4) foundations and understanding, $10 \% \quad$ (5) assessments and evaluation, 20\%, (6) instructional subject matters, 20\%; and (7) health and safety concepts, 5\%. Contents used for defining competencies are then listed in each of the corresponding areas. Four contents for defining competencies, for example, are listed in (5), including performance assessment (5.1), program goal and objectives (5.2), individualized instruction (5.3), and program evaluation (5.4).

In 1979, an APE task force was established for the development of professional competencies in the American Alliance for Health, Physical Education, Recreation and Dance [1]. The competencies identified for APE teachers by this task force are completed using three levels. The first level has six professional areas, including biological foundations; sociological foundations; psychological foundations; historical-philosophical foundations; assessments and evaluation; and curriculum planning, organization, and implementation. The second level is used for listing several contents in each of the six areas. In the psychological foundations, for example, four contents are listed, including human growth and development, motor learning, self-concept and personality development, and management of behavior. The third level is used for presenting multiple competencies for training APE teachers. Five competencies, for example, were identified in the content of motor learning in the area of psychological foundations. That "demonstrate understanding of human growth and develo0pment" is an example of the competencies in the content of motor learning in the area of psychological foundations [1] This resulted in that professional requirements for certification, licensure, and endorsement were created foe training APE teacher in several states.

Program requirements for APE endorsement were developed in Louisiana in 1979 [1]. An additional 12 credit hours were required for a regular PE teacher with a teaching licensure to earn an APE certification in Louisiana. Standards for an APE endorsement was created in Georgia in the same period of time. The Georgia APE endorsement required a person to complete the minimum 20 quarter hours to obtain competencies from eight categories for teaching students with disabilities [1]. Minnesota requirements for APE licensure established required a person to take courses with at least 27 quarter hours or the equivalent for being eligible to teach APE classes [1]. Michigan requirements for APE certification developed required a person to complete courses with 9 semester hours or 12 term hours after earning a valid teaching certificate. Alabama requirements for APE certification required a person to complete courses with 12 semester hours or 20 quarter hours after earning a valid teaching certificate for employment of APE teachers [1].

Based on the above requirements, master's degree programs for training APE teachers have been created at colleges and universities in the United States of America. In 1983, for example, a master degree program specially designed for preparing APE teachers was initiated at Western Michigan University and approved by Michigan Department of Education [11]. This program requires a student to complete 36 credit hours to obtain APE competencies required by Michigan Department of Education to earn a master's degree in APE. Other mast master's degree programs developed in other colleges and universities; however, might require a student to complete a different total of credit hours to obtain APE competencies required by different states.

The different requirements for training APE teachers by different state have resulted in different competencies for APE teachers. APE professionals then believed that nationwide standards for preparing APE teachers should be established. In 1995, APENS (i.e., Adapted Physical Education National Standards as presented before) were developed [6]. These standards were revised over the years 2003-2006 to reflect current knowledge and practice in the APE field. A five-level system were used for 15 standards (i.e., human development, motor behavior, exercise science, measurement and evaluation, history and philosophy, curriculum theory and development, unique attributes of learners, assessment, instructional design and planning, teaching, consultation and staff development, student and program evaluation, continuing education, ethics, and communication). The first three levels were developed for regular PE teachers and the last two levels were specific competencies designed for APE teachers. These standards have been infused in APE training programs [6] that are currently offered in the nation.

Since APENS has been published, all master's degree program in APE have been updated based on competencies specified in APENS. More similarities among these program are currently observed and identified. However, differences among these program are still demonstrated. In the 2017 conference of the National Consortium for Physical Education for Individual with disabilities, Chad, Block, and Wilson gave a presentation about a survey of graduate program in APE [12]. The results of this survey reviewed that a total of 34 APE graduate programs were offered at colleges and universities represented 17 states in the United State of America. All of these program required students to take APE courses and complete practicum. Some differences, however, were also identified. The number of APE courses for completing a graduate program was 
different among APE graduate programs with a range from 2 to 9 courses, for example, while the contact hours of practicum for earning an academic degree was different among APE graduate programs with a range from 2 to 50 hours per week.

The results of this survey provided all APE professionals with the latest information about APE graduate programs offered in the United States of America. However, a descriptive profile for all master's degree programs in APE was not proposed in this presentation. As a matter of fact, a profile could not be proposed based on the results of this survey since some variables of this profile were not included in this survey. Such variables as the name of an APE program (e.g., APE or adapted physical activity), the name of a master degree (e.g., Master of Art of Master of Science), the number of credit hours for earning a master's degree (e.g., 30 or 36), the type of courses (e.g., core and elective), and top ranked APE courses (e.g., Assessment in APE) were not included in the survey complete by Chad, Block, and Wilson [12]. Therefore, a study is needed to create a descriptive profile for all master's degree program in APE in the United States of America

\section{Method}

A total of six procedures were employed in this study. These procedures were the list of data sources for retrieving all programs of study in APE, the definition of basic characteristics for analyzing all programs of study in APE, the number of coding components for collecting data from all programs of study in APE, the sheet of data collection for coding all programs of study in APE, the number of course groups for categorizing courses for all programs of study in APE, and the analysis of coding reliability for documenting the coding activities completed for all programs of study in APE. Each of the 6 procedures is presented below.

Two lists of the data sources for APE professional preparation programs posted on webpages by the National Consortium for Physical Education and Recreation for Individuals with Disabilities [13] and PE Central [14] were used as primary data sources to identify all APE master's degree programs offered in the nation. The program of study for a master's degree in APE or equivalent for each of the identified programs was then searched and downloaded as the raw data source.

The primary information is operationally defined as basic characteristics demonstrated by the downloaded programs of study. These basic characteristics referred to the university location; the professional name; the type of degree; the number of credit hours; whether a program of study awards an APE endorsement, includes research courses, offers elective courses, and teaches courses online; and whether the program requires students to complete a research project, field practicums in APE, and a comprehensive exam. These characteristics were identified from each of the downloaded programs of study and were then summarized.

The coding components refer to different parts of the downloaded programs of study. Coding components are defined as descriptive phrases developed for analyzing different parts of programs or contents of documents [15] [16]. Based on the structure of the program study in APE [17], a total of four phrases were identified as the coding components for analyzing each of the programs of study. The four phrases were categorized as follows: (a) core courses, (b) specialization courses, (c) elective courses, and (d) capstone courses.

A core course is defined not only as a required course in the APE program, but also as required course in other programs of study (e.g., research methods). A specialization course is defined as a course that is required only for students in APE (e.g., assessment in APE). An elective course is defined as a course that is selected by students in APE from another area (e.g., behavior analysis in special education). A capstone course is defined as a course that is designed to provide opportunities for students to integrate knowledge from the core and specialization courses in professional research and practice (e.g., field experience).

All downloaded programs of study were coded using a Coding Sheet for All Programs of Study for Master's Degrees in APE. The sheet was designed for coding each program of study into four categories. Two individuals completed the coding activity independently. One individual coded all downloaded programs of study, while another individual coded $50 \%$ of all downloaded programs of study. Neither individual had knowledge of the other's coding activity.

The courses coded into a category were then grouped based on their similarities. In the category of core courses, 5 groups were formed, including (a) research methods, (b) statistics, (c) seminar and research, (d) independent studies, and (e) psychosocial foundation. In the component of specialization courses, 3 groups were formed, including: (a) APE, (b) kinesiology, and (c) special education. In the category of elective courses, eight groups were formed, including: (a) kinesiology, (b) therapy, (c) special education, (d) psycho-social classes, (e) APE, (f) general education, (g) research and statistics, and (h) not specified. In the category of capstone courses, 4 groups were formed, including: (a) project and/or thesis, (b) practicum and/or field experience, (c) comprehensive examination, and (d) no capstone requirement.

The reliabilities for completing both coding activity and data grouping completed by two independent persons were estimated based on an inter-observer agreement method. A reliability 
coefficient was calculated with the agreement method, in which the number of agreements was divided by the number of agreements plus disagreements and then multiplied by 100 (Thomas and Nelson, 2000). The descriptive statistics, frequency and percent, were calculated for each of the categories and groups.

\section{Results}

Using all procedures for collecting and analyzing all data from all program of study in APE, a total of 7 results were obtained in this study. These results are the number of college and universities offering APE programs for master's degrees, the statistics of professional names used in APE programs of study, the statistics of academic degrees used in APE programs of study, the statistics of credit hours found in APE programs of study, the statistics of program characteristics in APE programs of study, the statistics of course groups in APE programs of study, and the statistics of top courses in each course group. Each of these results is presented below.

The results obtained in this study indicate that 31 colleges and universities currently offer master's degrees in APE or equivalent programs of study and post their programs of study online (Table 1). These colleges and universities are located in 20 states, including CA, CT, GA, HI, IL, IN, LA, MI, MN, NC, NE, NM, NY, OH, OR, PA, TX, UT, VA, and WI. Of the 31 colleges and universities, $23(74 \%)$ name the programs of study as APE (see Table 2) and 17 (55\%) award a Master of Science (see Table 3).

Table 1. Colleges and Universities Currently Offering Graduate Programs for Master's Degrees or Equivalents in the United States of America with Their Programs of Study Available Posted Online

\begin{tabular}{|c|c|c|}
\hline $\begin{array}{c}\text { Sequence } \\
\#\end{array}$ & $\begin{array}{c}\text { Names of Colleges and } \\
\text { Universities }\end{array}$ & State \\
\hline 1 & $\begin{array}{l}\text { California State Polytechnic } \\
\text { University, Pomona }\end{array}$ & $\mathrm{CA}$ \\
\hline 2 & $\begin{array}{c}\text { California State University, } \\
\text { Chico }\end{array}$ & $\mathrm{CA}$ \\
\hline 3 & $\begin{array}{c}\text { California State University, } \\
\text { Long Beach }\end{array}$ & $\mathrm{CA}$ \\
\hline 4 & $\begin{array}{c}\text { California State University, } \\
\text { Los Angeles }\end{array}$ & $\mathrm{CA}$ \\
\hline 5 & Bridge Water State University & CT \\
\hline 6 & University of Georgia & GA \\
\hline 7 & Georgia State University & GA \\
\hline 8 & $\begin{array}{c}\text { University of Hawaii at } \\
\text { Manoa }\end{array}$ & $\mathrm{HI}$ \\
\hline 9 & Northern Illinois University & IL \\
\hline 10 & Indiana University & IN \\
\hline 11 & Louisiana Tech University & LA \\
\hline 12 & $\begin{array}{c}\text { Southeastern Louisiana } \\
\text { University }\end{array}$ & LA \\
\hline 13 & Eastern Michigan University & MI \\
\hline 14 & Michigan State University & Ml \\
\hline
\end{tabular}

\begin{tabular}{|c|c|c|}
\hline 15 & Western Michigan University & $\mathrm{MI}$ \\
\hline 16 & $\begin{array}{c}\text { Minnesota State University, } \\
\text { Mankato }\end{array}$ & MN \\
\hline 17 & St. Cloud State University & MN \\
\hline 18 & University of Minnesota & MN \\
\hline 19 & East Carolina University & NC \\
\hline 20 & $\begin{array}{c}\text { University of Nebraska at } \\
\text { Kearney }\end{array}$ & NE \\
\hline 21 & University of New Mexico & NM \\
\hline 22 & $\begin{array}{c}\text { State University of New York, } \\
\text { Brockport }\end{array}$ & NY \\
\hline 23 & $\begin{array}{c}\text { State University of New York- } \\
\text { Cortland }\end{array}$ & NY \\
\hline 24 & Ohio State University & $\mathrm{OH}$ \\
\hline 25 & University of Toledo & $\mathrm{OH}$ \\
\hline 26 & Oregon State University & OR \\
\hline 27 & $\begin{array}{c}\text { Slippery Rock University of } \\
\text { Pennsylvania }\end{array}$ & PA \\
\hline 28 & Texas Woman's University & TX \\
\hline 29 & University of Utah & UT \\
\hline 30 & University of Virginia & VA \\
\hline 31 & $\begin{array}{l}\text { University of Wisconsin-La } \\
\text { Crosse }\end{array}$ & WI \\
\hline
\end{tabular}

Table 2. Frequencies and Percentages of Different Professional Names Used in the Programs of Study

\begin{tabular}{ccc}
\hline Names Used in the Programs & $f$ & $\%$ \\
\hline APE & 23 & $74 \%$ \\
APE/Activity & 4 & $14 \%$ \\
Adapted Physical Activity & 2 & $6 \%$ \\
Special PE & 2 & $6 \%$ \\
\hline
\end{tabular}

Table 3. Frequencies and Percentages of Different Types of Degrees Used in the Programs of Study

\begin{tabular}{ccc}
\hline Types of Degrees & $f$ & $\%$ \\
\hline Master of Science & 17 & $55 \%$ \\
Master of Art & 8 & $26 \%$ \\
Master of Education & 5 & $16 \%$ \\
Specialists & 1 & $3 \%$ \\
\hline
\end{tabular}

Tale 4. Means and Ranges of Total Credit Hours of the Programs of Study and Credit Hours in the Four Components of the Programs of Study

\begin{tabular}{ccc}
\hline $\begin{array}{c}\text { Program of Study } \\
\text { Component }\end{array}$ & $\begin{array}{c}\text { Credit } \\
\text { Hour } \\
\text { Mean }\end{array}$ & $\begin{array}{c}\text { Credit } \\
\text { Hour } \\
\text { Range }\end{array}$ \\
\hline Program of Study & 34 & $30-37$ \\
Core Courses & 5 & $0-6$ \\
Professional Courses & 18 & $12-24$ \\
Elective Courses & 5 & $0-17$ \\
Capstone Courses & 6 & $3-12$ \\
\hline
\end{tabular}

As presented in Table 4, the mean of the total credit hours over the 31 programs of study is 34 with a range from 30 to 37 . The mean of the credit hours in the category of core courses is 5 with a range from 0 to 6 . The mean of the credit hours in the category of specialization courses is 18 with a range from 12 to 24. The mean of the credit hours in the category of 
elective courses is 5 with a range from 0 to 17 . The mean of the credit hours in the category of capstone courses is 6 with a range from 3 to 12 .

As presented in Table 5, the different programs of studies show different characteristics. Of the 31 programs of study, 20 (65\%) are designed for earning an endorsement while earning a master's degree; 28 (90\%) require the students to take some research method courses; 24 (77\%) provide the students with opportunities to select courses in other areas; 20 $(65 \%)$ ask the students to complete research projects; $21(68 \%)$ require the students to complete field experience; and $9(29 \%)$ require the students to take a comprehensive exam before graduation. Currently, there are only $2(6 \%)$ programs delivering their courses online

In each of the four categories, specific frequency and percent were calculated based on groups. In the first category of core courses, 29 out of the 66 core courses $(44 \%)$ were coded as in the group of research methods, $16(24 \%)$ as in the group of statistics, 13 $(20 \%)$ as in the group of seminar and issues, $6(9 \%)$ as in the group of independent studies, and $2(3 \%)$ as in the group of psycho-sociologies (Table 6).

Table 5. Frequencies and Percentages of Different Programs of Study Based on Different Characteristics

\begin{tabular}{ccc}
\hline Program Characteristics & $f$ & $\%$ \\
\hline Earing an endorsement & & \\
Yes & 20 & $65 \%$ \\
No & 11 & $35 \%$ \\
\hline Taking research courses & & \\
Yes & 28 & $90 \%$ \\
No & 3 & $10 \%$ \\
Taking electives courses & & \\
Yes & 24 & $77 \%$ \\
No & 7 & $23 \%$ \\
Doing research projects & & \\
Yes & 20 & $65 \%$ \\
No & 11 & $35 \%$ \\
Doing field experiences & & \\
Yes & 21 & $68 \%$ \\
No & 10 & $32 \%$ \\
A Comprehensive Exam & & \\
Yes & 9 & $29 \%$ \\
No & 22 & $71 \%$ \\
\hline Yes & & \\
No & 2 & $6 \%$ \\
\hline & 29 & $94 \%$ \\
\hline
\end{tabular}

In the second category of specialization courses, three groups of courses were formalized. Of the 283 professional courses identified in this category, 113 $(60 \%)$ were coded as in the group of adapted physical activity, $54(22 \%)$ as in the group of kinesiology, $21(22 \%)$ as in the group of special education, and 1 $(0.5 \%)$ as in the technology (Table 6). The top three courses in adapted physical activity are assessment, introduction, and programming (Table 7). The top three courses in kinesiology are curriculum, inclusion, and instructional strategies (Table 7). The top three courses in special education are behavior management, collaboration, and exceptionalities (Table 7).

In the third category of elective courses, eight groups of courses were developed. Of the 72 elective courses, $43(60 \%)$ were coded as in the group of kinesiology, $6(8 \%)$ as in the group of therapy, $6(8 \%)$ as in the group of special education, $6(8 \%)$ as in the group of psycho-social courses, $5(7 \%)$ as in the group of adapted physical activity, $4(6 \%)$ as in the group of the general education, $3(4 \%)$ as in the group of research and statistics, and $19(26 \%)$ as in the group of not specified (Table 6).

In the fourth category of capstone courses, four groups of courses were formed. Of the 43 capstone courses, $20(47 \%)$ were coded as in the group of practicum/field experience, $14(33 \%)$ were coded as in the group of research project and/or thesis, $6(14 \%)$ were coded as in the group of comprehensive examination, and $3(7 \%)$ were coded as in the group of no requirements (Table 6).

Table 6. Frequencies and Percentages of Different Groups in each of the Four Components of Analysis

\begin{tabular}{ccc}
\hline Course Groups & $f$ & $\%$ \\
\hline In core & & \\
Research methods & 29 & $44 \%$ \\
Statistics & 16 & $24 \%$ \\
Seminar and issues & 13 & $20 \%$ \\
Independent studies & 6 & $9 \%$ \\
Psycho-sociologies & 2 & $3 \%$ \\
In specialization & & \\
Adapted physical activity & 113 & $60 \%$ \\
Kinesiology & 54 & $22 \%$ \\
Special education & 21 & $11 \%$ \\
Technology & 1 & $0.5 \%$ \\
In Elective & & \\
Kinesiology & 43 & $60 \%$ \\
Special education & 6 & $8 \%$ \\
Therapy & 6 & $8 \%$ \\
Psycho-social foundations & 6 & $8 \%$ \\
Adapted physical activity & 5 & $7 \%$ \\
General education & 4 & $6 \%$ \\
Research and statistics & 3 & $4 \%$ \\
Not specified & 19 & $26 \%$ \\
In capstone & & \\
Practicum/field experience & 20 & $47 \%$ \\
Research project/thesis & 14 & $33 \%$ \\
Comprehensive exam & 6 & $14 \%$ \\
No capstone requirements & 3 & $7 \%$ \\
\hline
\end{tabular}


Table 7. Frequencies and Percentages of Top Five Courses in Each of the First Three Groups in the Category of Specialization Courses

\begin{tabular}{ccc}
\hline Groups & $f$ & $\%$ \\
\hline Adapted Physical Activity & & \\
\hline Assessment & 18 & $16 \%$ \\
Introduction & 15 & $13 \%$ \\
Programming & 13 & $12 \%$ \\
Physical disabilities & 9 & $8 \%$ \\
Developmental disabilities & 6 & $5 \%$ \\
Kinesiology & & \\
Motor development & 8 & $20 \%$ \\
Curriculum & 7 & $17 \%$ \\
Motor learning & 4 & $10 \%$ \\
Measurement Evaluation & 3 & $7 \%$ \\
Teaching effectiveness & 3 & $7 \%$ \\
Special Education & & \\
Behavior Management & 6 & $29 \%$ \\
Collaboration & 5 & $24 \%$ \\
Exceptionalities & 2 & $10 \%$ \\
Introduction & 2 & $10 \%$ \\
Inclusion & 1 & $5 \%$ \\
\hline
\end{tabular}

\section{Discussion}

Based on all results obtained in this study, a descriptive of all programs of study for master's degrees in APE can be proposed for professionals in APE. This profile shows that most programs of study for training APE teachers use APE to name their programs for which students earn a Master of Science by completing a mean total of 34 credit hours, in which research courses, elective courses, research projects, and field experience are most likely requirements, and for which a high possibility exists for a student to earn an endorsement at the same time they are receiving a master's degree. This profile provided information about top course groups in the core, specialization, elective, and capstone components and about top specific courses in each of the course groups as well.

There are at least four aspects of this profile are valuable for further discussion. These aspects are APE being used as the program name in most APE programs of study, a Master of Science after completion of 34 credit hours being awarded by most APE programs of study, several characteristics being dominated in most APE programs of study, and some courses being prioritized in most APE programs of study. Each of these 4 aspects is presented below.

First, most programs use APE as the program name. As presented in Tables 2, 74\% (23/31) of the downloaded programs of study use APE and $14 \%$ (4/31) use APE/activity, showing that APE master's degree programs currently offered at colleges and universities are primarily designed for preparing APE teachers with a focus on modification of traditional physical education [18].
Second, most programs award a Master of Science after completion of 34 credit hours. As presented in Table 3, 55\% (17) of the programs of study award a Master of Science, showing that most APE professionals believe in the APE field being established based on a scientific basis [19], which requires completion of more than 30 credit hours in order to earn a master's degree program in APE. As presented in Table 4, the mean of credit hours across 31 download programs of study is 34 with a range from 30 to 37 , in which about a half of credit hours are distributed in professional components (18 credit hours).

Third, other types of characteristics are dominated on the downloaded programs of study as well. As shown in Table 5, most programs award an APE endorsement $(65 \%)$ and require all students to complete research courses $(90 \%)$, elective courses $(77 \%)$, research projects $(65 \%)$, and field experience $(68 \%)$, which are consistent with the professional philosophes reflected in the APENS (Kelley, 2006). However, most programs do not require all students to complete a comprehensive exam before graduation (71\%) and do not offer students the option to take their courses online (94\%), showing that most students in APE programs graduated by completing courses specified in the programs of study in a traditional face-to-face setting.

Fourth, some courses are prioritized in most downloaded programs of study as shown in Table 6 . In the core component, the top two course groups students are to take are research methods and statistics, which is consistent with all types of graduate programs [20]. In the specialization component, the top three course groups are adapted physical activity, kinesiology, and special education, which are highly recommended in the APE field [4] [19]. In the elective component, the top four course groups are kinesiology, special education, therapy, and psycho-social foundations, which are fully supported by national standards [6]. In the capstone component, the top two course groups are practicums or field experiences and a research project or thesis, which is consistent with all types of graduate programs [20].

It should be noted that in the component of specialization, as presented in Table 7, some specific courses that students are required to take in each of the top three course groups are valuable for further discussion. In the adapted physical activity group, the three specific courses that students are required to take are assessment in APE, introduction to APE, and APE programming. In the kinesiology group, the three specific courses that students are required to take are motor development, curriculum building, and motor learning. In the special education group, the three specific courses that students are required to take are behavior managements, collaborations, and exceptionalities. It seems then that these courses 
should serve as the foundation for the development of a master's degree program in APE by a university.

It is very clear that the descriptive profile of all programs of study for master's degrees in APE obtained in this study provides all professionals in APE a useful reference of developing a program of study for a master's degree in APE. If a professor at a college or university in APE is required or interested in developing a new program of study for a master's degree in APE, this professor is able to check the descriptive profile of all programs of study for master's degrees in APE obtained in this study to determine what name should be used, how many credit hours should be taken, what courses should be included, and so on, for the program of study this professor wants to develop.

As shown in Table 8, for example, a professor in a college or university may create a 33 credit-hour program of study for a master of science degree in APE based on the descriptive profile presented in this study. Since the profile indicates that the mean of credit hours across all APE programs of study is 34, most APE programs of study use APE as the professional name of their programs of study (74\%), and most APE programs of study use the master of science as the degree name of their programs of study (55\%), the program created in Table 8 is therefore named as a 33 credit-hour program of study for a master of science degree in APE.

Table 8. A 33 Credit-Hour Program of Study for a Master of Science Degree in APE Created Based on the Descriptive Profile Obtained in This Study

\begin{tabular}{cc}
\hline Components (Credit Hours) & $\begin{array}{c}\text { Credit } \\
\text { Hours }\end{array}$ \\
\hline Course Tittle & 3 \\
In core (6 Credit Hours) & 3 \\
Research methods & \\
Statistics & 3 \\
In Specialization (18 credit hours) & 3 \\
\hline Assessment in APE & 3 \\
Introduction to APE & 3 \\
Programming in APE & 3 \\
Behavior Management & \\
Collaboration & \\
Motor development & 3 \\
In Elective (3 Credit hours) & 3 \\
Curriculum In PE & 3 \\
Motor learning & 3 \\
Teaching effectiveness in PE & 3 \\
Exceptionalities in SPED & 3 \\
Introduction to SPED & \\
Inclusion in PE and SPED & 3 \\
In Capstone (6 credit hours) & 3 \\
\hline Practicum experience & \\
Research project &
\end{tabular}

In the component of core, two courses (research methods and statistics) are included in this program of study because they are ranked as the top two courses in the core in Table 6 . In the component of specialization, five courses (assessment in APE, introduction to APE, programming in APE, behavior management, and motor development) are included in this program of study because the first three are ranked as the top three courses in the adapted physical activity, the fourth and fifth courses are ranked as the top two in the special education, and the last one is tanked as the top one in the kinesiology in Table 6 . In the component of elective, 6 courses are available for a student to select one course to take since all 6 courses are included in Table 7. In the component of capstone, two courses (practicum experience and research project) are included in this program of study because they are ranked as the top two courses in the capstone in Table 6 .

\section{Summary}

In summary, the findings obtained in this study provided a descriptive profile of all programs of study for master's degrees in APE. This profile shows that most programs of study for training APE teachers use APE to name their programs for which students earn a master of science degree by completing a mean total of 34 credit hours, in which research courses, elective courses, research projects, and field experience are most likely requirements, and for which a high possibility exists for a student to earn an endorsement at the same time they are receiving a master's degree. This profile also provided information about top course groups in the core, specialization, elective, and capstone components and about top specific courses in each of the course groups. It is clear that the profile developed in this study is useful for professionals in the development and revision of APE master's degree programs.

\section{References}

[1] K. P. DePauw and E. Bundschuh, Vintage years: Competencies, Certification, and Licensure in Adapted Physical eEducation. In C. Shrill (Ed.), Leadership training in adapted physical education (pp. 289-300). Champaign, IL: Human Kinetics, 1988.

[2] J. Zhang, K. Cowell, A. Rapelje, C. Farr and Z. Chen, A Descriptive Program of Study for Master's Degrees in Special (Adapted) Physical Education. A paper presented at the 2014 National Alliance for Health, Physical Education, Recreation and Dance, St. Louis, MO 2014.

[3] AAHPER (American Association for Health, Physical Education, and Recreation), Guideline for Professional Preparation Programs for Personnel Involved in Physical Education and Recreation for the Handicapped. Washington, DC: Author, 1973.

[4] C. Sherrill, Contemporary Adapted Physical Education Teacher Training: A History Beginning with 1967. In C. Shrill (Ed.), Leadership Training in Adapted Physical 
Education (pp. 289-300). Champaign, IL: Human Kinetics, 1988.

[5] W. Ersing and R. Wheeler, "The status of Professional Preparation in Adapted Physical Education", American corrective Therapy Journal, 25(4), 111-118, 1971.

[6] L. Kelly, Adapted Physical Education National Standards. Champaign, IL: Human Kinetics, 2006.

[7] J. Zhang, A. Rapelje, C. Farr, K. Cowell, and Z. Chen, Curriculum Features of Master's Degree Programs in Adapted Physical Education in the United States of America, A paper presented at the 2012 Conference of National Consortium for Physical Education and Recreation for Individuals with Disabilities, Reston, VA, 2012.

[8] E.A. Davies, An Analysis of Corrective Physical Education in Schools with Implications for Teacher Education. Unpublished doctoral dissertation, Teachers College, Columbia University, New York, 1950.

[9] R.A. Snyder and H.A. Scott. Professional Preparation in Health, Physical Education, and Recreation, New York: McGraw-Hill, 1954.

[10] California State Task Force on Standards for Professional Preparation in Adapted Physical Education. Scope and Content in Adapted Physical Education, Los Angeles: California State University, 1978.

[11] J. Zhang, J., J. Lewis, J., and Y. Liu. Project for Using a Hybrid Online Master's Degree Program Preparing Qualified Adapted Physical Education Teacher A proposal submitted to the US Department of Education, 2010

[12] N. Chad, M. Block, and W.J. Wilson. Analysis of Graduate Program in Adapted Physical Education. A paper presented at the 2017 Conference of National Consortium for Physical Education for Individuals with Disparities, VA, 2017.

[13] NCPERID. "Adapted Physical Education Programs." http://www2.gcs.k12.in.us/ldoherty/index_files/index/Web $\% 20$ sites $\% 20$ for $\% 20$ Adaptive $\% 20$ P.E/NCPERID $\% 20 \mathrm{Hom}$ epage.htm, (Access date: 15 June, 2015).

[14] PE Central. "Adapted Physical Education Programs." http://www.pecentral.org/adapted/adaptedwhatis.html,

(Access date: 15 June, 2015).

[15] D. Duncan, "Content analysis in health education research: An introduction to purposes and methods", Health Education, 20(7), 27-31, 1989.

[16] P.H. Johnson, and M.J. Kittleson, "A content analysis of health education teaching strategy/idea articles: 19701998”, Health Education, 31(5), 292-298, 2000.

[17] J. Zhang, Annual Grant Performance Report to US Department of Education for Implementing the Integrated Recreational Sport Activity Program for Young Adults with
Disabilities in 2009-2010. A report submitted to the US Department of Education, 2010.

[18] J.M. Dunn and C. A. Leitschuh, Special Physical Education, Dubuque, Iowa: Kendall/Hunt Publishing Company, 2010.

[19] C. Sherrill, Adapted Physical Activity, Recreation and Sport: Crossdisciplinary and Lifespan (6 ed.), Boulevard, IA: Brown and Benchmark, 2004.

[20] J.R. Thomas and J. K. Nelson, Research Methods in Physical Activity, Campaign, IL: Human Kinetics, 2000. 